This is the author's Post-print version (final draft post-refereeing as accepted for publication by the journal). The definitive, peer-reviewed and edited version of this article is published as: Permentier M., van Ham M. and Bolt G. (2008) Same Neighbourhood ... Different Views? A Confrontation of Internal and External Neighbourhood Reputations. Housing Studies 23, 833-855.

http://dx.doi.org/10.1080/02673030802416619

\title{
Same neighbourhood... different views? A confrontation of internal and external neighbourhood reputations
}

\author{
Matthieu Permentier*, Maarten van Ham** \& Gideon Bolt ${ }^{* * *}$ \\ * \& **** Utrecht University, Urban and Regional research centre Utrecht (URU), Utrecht \\ University, P.O. Box 80115, 3508 TC Utrecht, The Netherlands. Phone: +31-30- \\ 2531392, e-mail: ${ }^{*}$ m.permentier@geo.uu.nl, ***g.bolt@geo.uu.nl \\ ${ }^{* *}$ University of St Andrews, Centre for Housing Research (CHR), School of \\ Geography \& Geosciences, Irvine Building, North Street, St Andrews, Fife, KY16 \\ 9AL, UK. Phone +44(0)1334 463912, Fax +44 (0)1334 463949, e-mail: \\ maarten.vanham@st-andrews.ac.uk
}

\begin{abstract}
Residents and non-residents are likely to think differently about a neighbourhood's reputation. Relatively little is known about the similarities and differences between these internal and external types of neighbourhood reputation or the relationship between reputations and 'real' or 'objective' neighbourhood characteristics. This paper addresses two points: first, the extent to which neighbourhood reputations differ between and within groups; second, the extent to which these neighbourhood reputations are associated with measured neighbourhood characteristics. Data from a specially designed survey carried out in 24 neighbourhoods in Utrecht - the fourth largest city in the Netherlands - are used. Analysis of the data showed that neighbourhood reputations are rated higher by residents and estate agents than by other city residents. Within the group of other city residents we found differences in how neighbourhood reputations are rated by socioeconomic status, ethnicity, and educational background. Further, we found that neighbourhood reputations are correlated with measured social characteristics of the neighbourhood, while physical and functional neighbourhood characteristics are of less importance.
\end{abstract}

Keywords: neighbourhood reputations; residents; non-residents; neighbourhood characteristics; The Netherlands

\section{$1 \quad$ Introduction}

The neighbourhood effects literature suggests that a neighbourhood's bad reputation can have a negative effect on residents' social opportunities (Galster, 2007; Musterd and Andersson, 2005). Living in a stigmatized neighbourhood has been found to have a negative influence on the residents' job opportunities (Bauder, 2002; Wilson, 1996) 
and self-esteem (Taylor, 1998). It has also been suggested that neighbourhood reputations can have an effect on the behaviour of residents, who may adjust their social actions (within and outside their neighbourhood) in accordance with the area's ill repute among outsiders (see for example Galster and Killen, 1995). People take neighbourhood reputations into account when making their choices of where to live, to work or to locate a business (Wacquant, 1993).

Neighbourhood reputations do not naturally exist, but are socially constructed based on, for example, (personal) experiences, information from the media and easily observable functional and physical attributes of neighbourhoods. The concept of reputation is often used by policy makers and academics but it is hardly ever defined in a clear way. An important attribute of the neighbourhood reputation concept is that residents and non-residents - including other city residents (OCR) and, for example, estate agents - may think differently about the reputation of the same neighbourhood (see for example Skifter Andersen, 2001; Hastings and Dean, 2003). Only a limited number of authors back up the theoretical division of internal and external reputation with empirical data (see for example Hastings and Dean, 2003), while little is known about the degree of the differences between internal and external neighbourhood reputations.

Both residents and non-residents may construct neighbourhood reputations based on information which is not necessarily accurate. For example, the media might paint a misleading image of a neighbourhood by constantly highlighting one specific negative aspect. Neighbourhood reputations might also reflect a negative aspect of a neighbourhood which has much improved over time without the reputation improving. We know little about the extent to which neighbourhood reputations relate to objective neighbourhood characteristics. Different factors can be of importance: physical factors (the cleanliness of an area, building type, maintenance), functional factors (location and accessibility, presence of services), and social factors (ethnic composition, income levels). One may argue that functional and physical factors are the most important, since these are the most obvious cues for residents and nonresidents alike. On the other hand social characteristics might be of greater importance, because these are often covered in the media.

The rating of a neighbourhood's reputation is likely to be influenced by people's own characteristics in relation to the social characteristics of the neighbourhood. Residents and non-residents may give neighbourhoods higher ratings when the social composition of the neighbourhood matches their own characteristics. According to Schelling $(1969,1971)$, people do not want to be part of a minority population in their neighbourhood (see also Clark, 1991; Van Ham and Feijten, 2008; Van Ham and Clark, forthcoming). Thus a person whose characteristics differ from the characteristics of the majority of the residents in a neighbourhood is likely to give a lower rating to the neighbourhood than would people whose characteristics match those of the neighbourhood population.

This paper contributes to the existing literature on neighbourhoods and neighbourhood reputations by reporting an empirical investigation of the theoretical division of internal and external neighbourhood reputations. First, the extent to which neighbourhood reputations differ between residents and non-residents and within the group of other city residents is explored. Second, the paper describes the extent to which neighbourhood reputations are associated with objective neighbourhood characteristics. Our results have the potential to contribute to a more sophisticated understanding of the neighbourhood reputation concept so popular with policy makers and academics. In the empirical part of the paper we draw on data collected in the 
spring of 2006 in the city of Utrecht, The Netherlands. Information on 1,102 residents in 24 different neighbourhoods and 38 real estate agents was collected.

\section{Internal and external reputation}

Reputations can be attached to multiple objects, varying from companies to celebrities. Places are no exception to the labelling process: countries, regions, cities, and neighbourhoods all have reputations associated with them. According to Hortulanus (1995): "Reputation refers to the meaning and esteem residents and other involved parties attribute to a neighbourhood. Reputation also refers to the relatively stable image a neighbourhood has among city residents and to its place in the urban neighbourhood hierarchy" [translation from Dutch]. In the neighbourhood literature, the terms stigma and image are often used as an alternative for the term reputation. According to Hortulanus (1995), the concept of reputation has a more neutral resonance than stigma or image. The definition of reputation implies that the image of a neighbourhood needs to be widespread in order to constitute a reputation. However, different - and relatively small - groups can hold different ideas about the reputation of a place.

Neighbourhood reputations are likely to be based on the perceptions of both outsiders (non-residents) and residents. Curtis and Jackson (1977) argue that these groups hold similar views of neighbourhoods and found a strong correlation between residents' and non-residents' ratings of neighbourhoods. Residents may internalize the reputation created by outsiders and so give similar ratings. Blokland (2008) showed that residents in a housing project in New Haven (Connecticut) share the outsider's view that living in subsidized housing is "for failures" (cf. Wacquant, 1993). However, this does not imply that stigmatisation is imposed from outside and that residents of stigmatised neighbourhoods do not have a role to play. Blokland (2008, p. 34) argues that the stigmatisation comes about relationally: "The marked and the markers both matter, or more precisely their relations do." Her ethnographic analysis of a community meeting in a ghetto in New Haven, Connecticut, showed how discussions between officials and residents reinforced the stigma of the ghetto as a place of passive, dependent and disengaged residents.

A strong correlation between residents' and non-residents' evaluations of a neighbourhood does not necessarily mean that these groups rate neighbourhoods in the same way. Several authors argue that residents hold a different idea of the (reputation of their) neighbourhood than non-residents do (Skifter Andersen, 2001; Arthurson, 2001; Hortulanus, 1995, Hastings and Dean, 2003; Murie et al., 2003; Wassenberg, 2004), but there is little empirical support for this idea. The literature generally distinguishes two types of reputation: an internal reputation - the reputation the residents hold of their neighbourhood; and an external reputation - the neighbourhood's reputation among non-residents.

The first reputation type, the internal reputation, is thought to consist of a detailed view based on a neighbourhood's physical and social attributes (Hortulanus, $1995)^{1}$. Residents are familiar with their own environment, so they are thought to be capable of distinguishing a micro hierarchy of areas within a neighbourhood; for example 'good' and 'bad' streets and area sub-sections (Evans, 1980). Residents can

\footnotetext{
${ }^{1}$ Besides the internal and external reputation, one can also discern the perceived neighbourhood reputation. This is the view that individuals hold as to how the reputation of their own neighbourhood is viewed by other city residents (see Skifter Andersen, 2008).
} 
be expected to rate their neighbourhood higher than non-residents do because of selection effects; people choose to live in an area they find attractive or at least acceptable (Bell et al., 1996; Clark and Cadwallader, 1973). A second explanation could be that residents with no choice regarding their neighbourhood, and with little prospect of any improvement, may show a psychological adaptation to their situation and rate their neighbourhood relatively high, because it is the best they can get (see Festinger, 1957 on cognitive dissonance reduction).

The reputation among non-residents, the external reputation, is the second type of reputation. The category of non-residents or outsiders is very diverse: it consists not only of other city residents, but also of council workers, estate agents, police officers, teachers, and so forth. These groups assess neighbourhoods based on less information and less personal experience with the area than neighbourhood residents do. The views of the non-residents consist of simplified images of neighbourhoods, which are shaped by drawing sharp boundaries and exaggerated differences between neighbourhoods (Suttles, 1972). These boundaries are used to make the city comprehensible for daily activities: 'is it safe to go here'; and status considerations: 'what sort of people live here?' In addition, these boundaries enable residents of areas to establish and (re)confirm the status of their own area toward other city residents (Palmer et al., 2004, p. 420).

\section{Neighbourhood reputations and neighbourhood characteristics}

Neighbourhood reputations are based on the information people have on neighbourhoods. This information can be gained by experience, through the media or rumours, but reputations can be expected, at least in part, to be related to measurable 'real' or 'objective' neighbourhood characteristics. This section explores the relationship between neighbourhood characteristics and neighbourhood reputations as found in the literature. A distinction is drawn between functional, physical, and social factors.

Before turning to these factors, it is important to stress the relevance of a neighbourhood's history. Some authors (Logan and Collver, 1983; Hortulanus, 1995) argue that reputations are affected less by recent neighbourhood conditions than those from a previous age. Every place has a history (Massey, 1995) that may well play a part in the area's current reputation. The history of a neighbourhood might result in a more negative or positive reputation than the current characteristics would seem to predict (Power, 1997). For example, the North Tyneside neighbourhood of Meadow Well in Northeast England has a notorious name among city residents owing to its original status of a slum clearance area, in which only people of ill repute were thought to live (Hastings and Dean, 2003). Even though a neighbourhood may have improved significantly, its past can have a negative influence on the reputation of an area for a long time.

\subsection{Functional factors}

Functional characteristics of a neighbourhood consist of the location and accessibility of an area and the presence of such facilities as shopping centres, medical facilities, and green spaces. The location of a neighbourhood can be an important factor relating to its reputation (Logan and Collver, 1983; Power, 1997; Hastings and Dean, 2003). Costa Pinto (2000) found that the residents of stigmatized neighbourhoods in Portugal thought that the location and the poor accessibility of their neighbourhood were partly 
responsible for its negative reputation. An eccentric position can function as an enclave for prosperous households who express their social standing by living in isolation (Burgess, 1967). But on the other hand, an isolated location can be perceived as the spatial isolation of groups, emphasizing their separateness. The residents of isolated neighbourhoods are literally outsiders: people with different norms and values who do not blend in with the rest of the city (Hastings and Dean, 2003; Power, 1997, p. 272; Semyonov and Kraus, 1982).

According to Hortulanus (2000), relative to other factors, the presence of facilities is not important for neighbourhood reputations. Others have suggested that facilities may play a part, but only when they are extreme in nature. Less prestigious facilities such as a rehabilitation centre may have a negative effect on a neighbourhood's reputation (May, 2004, p. 2177). The presence of a notorious school can be detrimental (Skifter Andersen, 2008). Conversely, prestigious facilities can radiate prestige: an upmarket shopping centre may symbolize the residents' exclusive lifestyle (Suttles, 1972, p. 253).

\subsection{Physical factors}

A range of physical neighbourhood characteristics such as general aesthetics, building density, the maintenance of buildings and public space, and the spatial arrangement of infrastructure, green spaces and dwellings can be expected to affect a neighbourhood's reputation (Gärling, 1976). Van der Meer (1996) pointed out that the mix of dwelling types, size and quality and housing tenure in a neighbourhood all influence the image people have of a neighbourhood (see also Hortulanus, 2000; Brattbakk and Hansen, 2004; De Decker and Pannecoucke, 2004). The quality of the housing stock is often related to the construction period of the neighbourhood (Burgess, 1967; Power, 1997; Semyonov and Kraus, 1983). Neighbourhoods constructed between the 1950s and 1970s are more likely to have a poor reputation than pre-war neighbourhoods. Besides the construction quality, also the dominating architectural style of a neighbourhood influences the image people have of a neighbourhood (Costa Pinto, 2000; Skifter Andersen, 2002; Murie et al., 2003; Brattbakk and Hansen, 2004; Wassenberg, 2004). Many city residents consider large housing estates to be massive, monotonous, and alien, because of their deviation from other residential areas (Costello, 2005). The quality of high-density neighbourhoods is often rated as lower than the quality of neighbourhoods with extensive open spaces (Garcia-Mira et al., 1997).

Broken windows or other minor forms of public disorder such as graffiti or scattered garbage are also thought to be factors that influence neighbourhood reputations (Wilson and Kelling, 1982). These physical consequences of vandalism, crime and neglect can be perceived as a cue to residents and non-residents that 'no one in this neighbourhood cares' (see also Harris, 2001). According to Teijmant (1979), the importance of physical attributes lays not so much in their intrinsic appearance as in their socio-cultural interpretation: the built environment as a symbol of lifestyle. Residents, but especially outsiders, see and judge the built environment in relation to its inhabitants: physical attributes can give outsiders a general picture of the inhabitants' status and way of life (Suttles, 1972, Arthurson, 2001). In this way the physical characteristics of an area can be used as an indicator of its social characteristics. 


\subsection{Social factors}

The sociocultural and socioeconomic composition of neighbourhoods are thought to be the most important factors influencing their reputation (Keller, 1968; Gärling, 1976; Hourihan, 1979; Wacquant, 1993; Van Kempen, 1994; Hortulanus, 1995; Garcia-Mira et al., 1997; Bauder, 2001). Suttles (1972) suggests that these characteristics mirror those in the stratification process of society as a whole: socioeconomic status (income and employment status), ethnicity/race, and level of education. Most people will rank high-income areas above low-income areas because of the perceived negative effects associated with living in poor areas (Harris, 2001). A research in 29 post-war housing estates in 16 different European cities indeed reveals that residents who perceive their estate as homogeneous (poor) think more negatively about the reputation of their neighbourhood than residents who perceive their estates as socially mixed (Musterd, 2008). In addition, Logan and Collver (1983) found that the most important factor in community reputation is socioeconomic status (see also Hwang and Murdock, 1998), while racial composition and population age are of less importance.

Neighbourhood reputations and the ethnic composition of neighbourhoods are strongly linked. Peillon (cited by Power, 1997, p. 150) noticed that the problematic reputation of the banlieues in France was strongly related to the overrepresentation of ethnic minorities. Conclusions for neighbourhoods in Portugal (Costa Pinto, 2000) and Denmark (Skifter Andersen, 1999 as quoted by Skifter Andersen, 2008) are similar: negative reputations are linked to the presence of ethnic minorities. The reasons why the ethnic composition of neighbourhoods has an effect on the reputation of a neighbourhood are diverse. One argument is the so called 'pure race hypothesis', which asserts that whites have a strong prejudice against blacks ethnic minorities and therefore also against black and ethnic neighbourhoods (Bobo and Zubrinksky, 1996). An alternative explanation is the 'racial proxy theory' (Harris, 2001) which asserts that undesirability of black and ethnic neighbourhoods is caused by poverty in these neighbourhoods and low- quality schools rather than the ethnic composition of the neighbourhood.

There is much debate whether the socioeconomic and ethnic composition of neighbourhoods have the same effect on neighbourhood reputation as seen by different groups. Some argue that there is no difference as all groups use the same factors in assessing neighbourhood reputations (Curtis and Jackson, 1977; Lauman et al., 1970, Semyonov and Kraus, 1982). Others suggest that the effect of these characteristics on reputations can be different for different groups of outsiders (Suttles, 1968). One reason why groups differ in the assessment of neighbourhoods may be that people tend to have a preference for neighbourhoods where the socioeconomic and ethnic characteristics of the majority of the population are similar to their own (Schelling, 1969, 1971). People generally give higher ratings to neighbourhoods with a population similar to their own characteristics than to neighbourhoods with different population characteristics (Clark, 1991, 1992; Bobo and Zubrinsky, 1996). Clark (1992) found in Los Angeles that whites have a preference for white neighbourhoods with a maximum of 25 percent blacks, while no whites wanted to live in neighbourhoods that were more than 60 percent black residents. Blacks on the other hand preferred neighbourhoods consisting of around 50 percent black residents (for comparable findings see Emerson et al., 2001; Ilhanfeldt and Scafidi 2004). Research in The Netherlands has shown that Dutch people living in neighbourhoods where ethnic minorities are overrepresented are more likely to express a wish to move and actually move than residents belonging to a non-western 
ethnic minority group (Bolt et al., 2008; Van Ham and Feijten, 2008; Van Ham and Clark, forthcoming). From the above, the conclusion has to be drawn that the effect of the ethnic composition on the assessment of the neighbourhood varies per ethnic group.

Harris (2001), found evidence that is not in line with the findings of the above group of authors. His findings suggest that neighbourhoods that are highly rated are rated similarly by both blacks and whites. This finding is corroborated by the fact that the racial composition of neighbourhoods has the same effect for blacks and whites as a predictor of perceived disorder in the neighbourhood (Sampson and Raudenbusch, 2004). At the same time, however, whites have been found to be more sensitive to disorder than blacks and are consequently more likely to move out when disorder arises. This bias in perception of disorder may be an important factor explaining residential segregation in the United States (Charles, 2003).

There is also evidence that the assessment of neighbourhoods is not only linked to the ethnic composition of the neighbourhood but also linked to the residents' socioeconomic status. Van Ham and Feijten (2008) found that the percentage of lowincome households in a neighbourhood had a positive effect on the wish to leave the neighbourhood for high-income households and a negative effect for low-income households. That finding is in line with Michelson's assertion (1977), that "people prefer to associate with others of their own class and values and they develop close associations with places with which they are familiar and consider conducive to their own style of living." In other words, Schelling's hypothesis that one's residential preferences can be influenced by one's own characteristics in combination with the characteristics of the neighbourhood population is relevant with respect not only to ethnicity, but also to socioeconomic characteristics.

\subsection{Hypotheses}

The above literature review led to the following hypotheses:

1. Neighbourhood residents assess the reputation of their neighbourhood significantly more positively than do other city residents or estate agents.

2. Social neighbourhood factors are more strongly related to neighbourhood reputation than physical and functional factors are.

3a. Native Dutch people assess the reputation of immigrant neighbourhoods more negatively than non-western immigrants do

3b. Individuals with a low socioeconomic status (income and education) assess neighbourhoods with a low socioeconomic status more positively than individuals with a high socioeconomic status do

\section{$4 \quad$ Research area and data}

Secondary data on how different groups rate the reputation of neighbourhoods was not readily available. We therefore carried out an extensive survey that concentrated specifically on neighbourhood reputations. The primary data collection for this study was carried out in 2006 in the city of Utrecht which is centrally located in the Netherlands and the fourth largest city of the country. Utrecht is a compact city with 281,011 residents (GBA City of Utrecht, 2006) and a diverse range of neighbourhoods in terms of population composition.

[FIGURE 1 AROUND HERE] 
Compared with the two largest cities in the Netherlands (Amsterdam and Rotterdam), the proportion of medium and highly-educated residents in Utrecht is high (Utrecht 69.4 percent, Rotterdam 47 percent, Amsterdam 56.4 percent, The Hague: unknown, data for 2004). Utrecht has a large university and Utrecht graduates find the city centre and surrounding neighbourhoods attractive residential environments. Partly as a result of the university connection, the city has a high percentage of residents under the age of 25. Compared with the other three cities, Utrecht has a low percentage of non-western immigrants (Utrecht 23.8 percent, Amsterdam 34.3 percent, Rotterdam 35.4 percent, The Hague 32.2 percent, GBA City of Utrecht 2006; O+S Amsterdam, 2006). The segregation index of non-western immigrants is similar to that of the three other cities (Utrecht, 37.4; Amsterdam, 36.3; Rotterdam, 38.5; The Hague, 46.1, Bolt et al., 2006). Non-western immigrants in Utrecht are predominantly concentrated in post-war housing estates, often located at the fringe of the city (the neighbourhoods Kanaleneiland, Overvecht and Hoograven), and in early twentieth century residential areas in the vicinity of former industrial sites (Lombok, Zuilen and Pijlsweerd).

Measuring neighbourhood reputations required the selection of (administrative) neighbourhoods that had a wide recognition among respondents. On the basis of a small telephone survey, aimed at understanding which neighbourhoods were known among the urban population, we selected 24 out of 38 neighbourhoods (representing 69 percent of the Utrecht population), and randomly selected addresses within them. A total of 1,389 paper questionnaires were collected in the spring of 2006 (response rate 44.1 percent). Questionnaires were distributed and collected in person. Since one neighbourhood was oversampled (Kanaleneiland), we used a proportionate sample of this neighbourhood for our analyses. This resulted in a total sample of 1,102 respondents. Respondents were asked to answer the following question regarding the reputation of their own neighbourhood: "How do you assess the reputation of your own neighbourhood?"(1 very poor - 5 very good). The reputation of other city-neighbourhoods was asked by the following question: "How would you assess the reputation of the following neighbourhoods?" (1 very poor -5 very good $)^{2}$.

The two largest minority groups in Utrecht - Turks and Moroccans - were underrepresented in our survey, especially in the largest ethnic neighbourhoods. Regarding age, there is an under representation of people between 18 and 44 and an overrepresentation of the group 45-64. Regarding household composition, our sample contains slightly fewer singles than the official statistics indicate, although these statistics can be expected to overestimate one-person households as there is no reliable registration of cohabiting couples. These characteristics of our sample should be taken into account in the interpretation of our results.

To obtain the reputations of the 24 neighbourhoods according to estate agents, a mailing was sent to all the estate agents in Utrecht $(n=56)$, which resulted in 38 collected questionnaires.

We are aware that the administrative neighbourhoods we used do not necessarily coincide with the perceived neighbourhoods of the residents (Galster, 2001; Kearns and Parkinson, 2001; Lee and Campbell, 1997). We asked all respondents to name their neighbourhood and the majority ( 81.5 percent) gave the same name as the administrative name of the area. Only 4.7 percent gave a very

\footnotetext{
${ }^{2}$ In the survey respondents were also asked how they thought that outsiders rated the reputation of respondent's neighbourhood (perceived reputation). Because internal reputation and perceived reputation are strongly correlated $(\mathrm{r}=0.74)$, we have not used the latter variable in our analyses.
} 
different name and 14 percent gave a name similar to the administrative name. Neighbourhood-level characteristics were collected from two different sources: the City of Utrecht (WistUdata and Buurtmonitors) and Statistics Netherlands (CBS).

\subsection{Measuring reputation}

We identified two different methods to measure neighbourhood reputations in the literature. According to the first method, respondents are asked to rank neighbourhoods ranging from the most preferred to the least preferred neighbourhood in which they would like to live and then the average scores of all respondents is taken. In this way, neighbourhoods are seen in relation to each other. Semyonov and Kraus's (1982) investigation of the reputation of 62 communities and 28 neighbourhoods in Israel found the categorization of neighbourhoods, based on prestige, to be hierarchical. Places were perceived as being organized in a system of stratification easily recognized by the population, an outcome supported by others (Curtis and Jackson, 1977; Hortulanus, 1995; Laumann et al., 1970; Logan and Cullver, 1984). A problem with the ranking method is that people seem able to indicate the best and the worst areas, but find it hard to distinguish between neighbourhoods in the middle (Clark and Cadwallader, 1973, Thill and Sui, 1993). It has also been observed that respondents have difficulties ranking large numbers of neighbourhoods or items (Adams, 1969; Congalton, 1961).

A second method to measure reputation as suggested by Thill and Sui (1993) is to use the average of the individual assessments of reputations. Instead of ranking neighbourhoods, respondents are asked to assign a rating to each individual neighbourhood. In this paper we have used this second method. To calculate a reputation score for a neighbourhood, the average score of all individual assessments is taken. To investigate the extent to which different neighbourhood-level variables, functional, physical, and social factors were related to neighbourhood reputations we used a linear multiple regression model.

\section{$5 \quad$ Analyses}

\subsection{Residents and non-residents ratings of neighbourhood reputations}

We started by investigating whether neighbourhood residents assess the reputation of their neighbourhood significantly higher than other city residents and estate agents do (hypothesis 1). Figure 2 shows the reputation ratings assigned by neighbourhood residents, other city residents (OCR), and estate agents. Figure 3 gives a graphical representation of the average reputation rating of 24 neighbourhoods given by other city residents. Neighbourhoods on the east side of Utrecht are given the highest reputation ratings, while neighbourhoods in the north and southwest are given the lowest ratings. The three neighbourhoods at the bottom of the hierarchy have certain characteristics in common. They are all post-war neighbourhoods, located on the fringe of the city, built in the period 1954-1975, consisting predominantly of apartment blocks with four to ten storeys. Another characteristic they share is that these neighbourhoods consist of predominantly social-rented housing, which partly explains the high percentage of non-western immigrants living in these areas. The neighbourhood of Kanaleneiland receives by far the lowest reputation rating from other city residents. In our view this is not so much the result of the nature of the neighbourhood as it shares many characteristics as well as problems with other low- 
ranked neighbourhoods. But in contrast to these neighbourhoods, Kanaleneiland is more pervasively slandered in both the local and national media (Permentier, 2003).

\section{[FIGURE 2 AROUND HERE]}

\section{[FIGURE 3 AROUND HERE]}

Interestingly, the neighbourhoods next to the bottom three, from Ondiep to Wijk C, are predominantly white blue-collar areas from the early twentieth century, with a large share of single-family housing. The top of the hierarchy is made up of neighbourhoods that were mostly built between the early 1900s and the 1930s. These neighbourhoods have a historic atmosphere, with relatively large and owner-occupied single-family houses that are generally considered visually attractive. Most of the residents are native Dutch with high incomes. Some of these neighbourhoods, like Wittevrouwen and Vogelenbuurt, have experienced gentrification over the last few decades, changing from unpopular areas to high-demand areas. Their rising popularity is the result of a combination of the rising demand for authentic houses in combination with their close proximity to the city centre. Neighbourhoods in the middle of the reputation hierarchy, such as Lombok, show similar, but more recent, trends of gentrification. If one looks at the size of the gap in ratings between residents and other city residents it becomes clear that differences in ratings are smallest for the neighbourhoods at the top of the hierarchy, while differences for the neighbourhoods at the bottom and the middle of the hierarchy are higher. Apparently there is more agreement between residents and other city residents about the status of top-ranked neighbourhoods than there is regarding low-and middle ranked neighbourhoods. This can probably be explained by the fact that it is not in the interest of residents of the low-and middle ranked neighbourhoods to be too negative about their own neighbourhood (Permentier, et al., 2007).

Interestingly, Figure 2 shows that estate agents rate neighbourhoods with a good reputation higher than neighbourhood residents do, while at the same time they give lower ratings to neighbourhoods with a poor reputation than the residents do. Thus, the differences between the extremes on the urban hierarchy according to the estate agents are greater than the differences between the neighbourhoods on the residents' and other city resident's neighbourhood hierarchy. A possible explanation is that estate agents link the variation in reputations to the large price differences of property between neighbourhoods. The statistical associations between the average ratings of the three groups are high. The correlation coefficients are 0.952 for residents and OCR; 0.937 for residents and estate agents; and 0.957 for OCR and estate agents. There is strong agreement among the three groups with regard to the positions of the neighbourhoods in the urban neighbourhood hierarchy.

Although the hierarchy of neighbourhoods with regard to their reputation is very similar for the three groups, there are differences in the total scores of the 24 neighbourhoods. Table 1 shows that, as expected, the average rating for neighbourhood residents is higher than for the other city residents and the estate agents, although the difference from the latter group is quite small. The lowest average standard deviation (SD) per neighbourhood, an indicator of the agreement within a group, is found among the estate agents, while the other city residents have on average the highest standard deviation. The knowledge of the other city residents about neighbourhoods can be expected to be the most limited and consequently there is more variety concerning the view on neighbourhood reputations within this group. 


\section{[TABLE 1 AROUND HERE]}

\section{[TABLE 2 AROUND HERE]}

To test whether neighbourhood residents and other city residents (including estate agents) differ in their rating of individual neighbourhoods we used a Student's T-test. The results in Table 2 show that with the exception of four neighbourhoods, neighbourhood residents rate their neighbourhood's reputation significantly higher than other city residents do $(\mathrm{p}<0.05)$. These empirical findings support the theoretical division between internal and external reputations for residents and other city residents. However, the number of significant differences in ratings between neighbourhood residents and estate agents is distinctly smaller (average difference in rating of 0.138). Estate agents differ in 12 cases from other city residents in their rating of a neighbourhood (average difference in rating of 0.241 ). These figures lead to the conclusion that the outsider group should not be seen as one homogenous group that hold similar ratings, but rather as a heterogeneous group consisting of diverse subgroups. Given the results, hypothesis 1 can be confirmed for the greater part as for the majority of neighbourhoods, neighbourhood residents rate their neighbourhood reputation higher than other city residents do. Interestingly, neighbourhood residents rate their neighbourhoods on average only slightly higher than estate agents do; only in less than a third of the neighbourhoods there is a significant difference.

\subsection{Neighbourhood reputations and neighbourhood characteristics}

To test the hypothesis that social neighbourhood factors are more strongly related to neighbourhood reputations than are physical or functional factors (hypothesis 2), we calculated one reputation rating for each neighbourhood $(n=24)$ by aggregating individual assessments. This aggregate is the dependent variable, while different (objective) social, physical, and functional factors, measured on the neighbourhood level, are introduced as independent variables. This procedure was followed for neighbourhood residents, other city residents, and estate agents.

Since the number of cases was limited in relation to the number of independent variables, a principal components analysis (PCA) was carried out. The goal was to reduce the original set of 20 neighbourhood characteristics to a set of unrelated components (to prevent multicollinearity) which between them, contain as many neighbourhood characteristics as possible. Table 3 presents the neighbourhood characteristics and the loadings on the 4 components. Together, these components account for 80.1 percent of the total variation. The first component can be interpreted as the socioeconomic/ethnic component. Neighbourhoods with high scores on this component are characterized by a high proportion of non-western immigrants and low socioeconomic status. Because the association between the ethnic and socioeconomic composition of the neighbourhood is so strong, it is impossible to separate the effects of the two neighbourhood characteristics. The second component, named the urbanity component, shows strong correlations with a number of physical aspects such as building density and age of the housing stock. The third component is named household composition/shops; it is associated with physical (multifamily dwellings), functional (number of shops), and social (single person households) neighbourhood characteristics. Neighbourhoods with high scores on this component are not attractive to family households. The fourth component is associated with sociodemographic 
characteristics, such as a high proportion of young people and a low proportion of elderly people.

\section{[TABLE 3 AROUND HERE]}

\section{[TABLE 4 AROUND HERE]}

To test our hypotheses we used three separate multiple linear regression model (see Table 4). ${ }^{3}$ All three measures of reputation are well accounted for by the predictors: the models have an $\mathrm{R}^{2}$ higher than 0.90 , indicating that at least 90 percent of the reputation is explained by the four components. The internal reputation model has the highest explained variance. The socioeconomic/ethnic component is the strongest predictor of internal reputation: a higher score on this component (suggesting a high percentage of deprived people, poorly-educated people and non-western immigrants) has a strong negative effect on the internal reputation. The second component, the urbanity component, has a positive effect on internal reputation, while the third component has a small positive effect.

The other city residents (OCR) reputation model shows fewer significant predictors than the internal reputation model: only the socioeconomic/ethnic component is highly significant and in the same direction. The estate agents' reputation model has two significant predictors, the most important of which is again the socioeconomic/ethnic component although the physical/accessibility component is also significant.

Although there are no substantial differences between the explained variance of the three models there are clear differences with regard to the number of significant predictors. The fact that, for the other city residents model, only a limited number of characteristics are important in the assessment of a neighbourhood's reputation is in line with Suttles' (1972) assertion, that other city residents only use a limited number of neighbourhood characteristics to assess neighbourhoods. While the socioeconomic/ethnic component is the only relevant factor for the other city residents, for estate agents the urbanity component is also a significant predictor. Interestingly, the urbanity component has a larger beta for the estate agents than for the residents $(0.236$ versus 0.186$)$. In other words, physical characteristics play a relatively large role in the way in which estate agents perceive a neighbourhood, which is in line with the research findings of Hastings and Dean (2003). The number of significant predictors is highest amongst the neighbourhood residents. This is the only group for which the third component (household composition/shops) has a significant effect, which reflects their detailed knowledge of their neighbourhood.

All three models have in common that the socioeconomic/ethnic component is by far the most important predictor of neighbourhood reputation. In all three models the predictor has a negative effect and the parameter has a relatively high value. Therefore, hypothesis 2 has to be confirmed. Although the components from the principal components analysis do not coincide neatly with the theoretical division of social, physical, and functional factors, the hypothesis is supported that social factors such as crime, poverty and ethnic composition, are most strongly related to neighbourhood reputations: in all three models the component that includes these three variables is the strongest predictor of neighbourhood reputation.

\footnotetext{
${ }^{3}$ The models fulfil the normality requirements
} 


\subsection{Individual characteristics and neighbourhood reputation assessment}

Figure 4 tests the hypothesis that native Dutch people assess the reputation of neighbourhoods with an overrepresentation of non-western immigrants more negatively than non-western immigrants themselves do (hypothesis 3a). The figure shows that neighbourhoods with a high percentage of non-western immigrants generally receive low reputation ratings. The relationship between the percentage of non-western immigrants and reputation rating is strong and significant for both nonwestern immigrants $(\mathrm{r}=-0.818 ; \mathrm{p}<0.000)$ and native Dutch $(\mathrm{r}=-0.807 ; \mathrm{p}<0.000)$ It is no surprise that the presence of a large group of non-western immigrants in neighbourhoods is associated with a lower reputation rating since the same neighbourhoods are often known for their socioeconomic problems. Both the native Dutch and the non-western immigrants give low reputation ratings to ethnic concentration-areas and high ratings to white neighbourhoods.

\section{[FIGURE 4 AROUND HERE]}

A more detailed analysis of the reputation ratings shows that non-western immigrants give a higher rating to ethnically mixed and ethnic concentration areas than the native Dutch do (average of 0.2 point higher than native Dutch for neighbourhoods with a high percentage of non-western immigrants and 0.2 for mixed neighbourhoods), while native Dutch rate white neighbourhoods higher (average of 0.2 higher). ${ }^{4}$ Testing the significance of the differences between the means shows that in the case of 9 neighbourhoods, native Dutch and non-western immigrants give significantly different reputation ratings. Neighbourhoods with a low percentage of non-western immigrants (below 12 percent) are rated higher by the native Dutch, and neighbourhoods with a higher percentage of non-western immigrants are rated lower by native Dutch. The three neighbourhoods where the percentage of non-western immigrants exceeds the 30 percent, do not even receive an average score above the 2.5 from the native Dutch. In the case of the neighbourhood Overvecht, second to the bottom of the hierarchy, it is striking that non-western immigrants are much more positive than native Dutch people. A possible explanation might be that the quality of housing in this relatively recent concentration neighbourhood is higher than in the 'traditional' immigrant neighbourhoods. Many non-western immigrants have moved from the traditional concentration areas to Overvecht and consider this as a major step forward in their housing career (Bolt, 2001). To the native Dutch, however, the large in-migration of non-western immigrants is perceived as a negative development. Taken together, these findings confirm hypothesis $3 \mathrm{a}$.

\section{[FIGURE 5 AROUND HERE]}

\section{[FIGURE 6 AROUND HERE]}

Figure 5 shows neighbourhood reputation ratings given by respondents from three different income groups (below $€ 1,600$; $€ 1,600-2,599$; and above $€ 2,600$ per month). The reputations of neighbourhoods accommodating mainly households with

\footnotetext{
${ }^{4}$ Neighbourhoods with a percentage of non-western immigrants lower than 12 percent are considered 'white' neighbourhoods; neighbourhoods with percentages between 12 and 24 are considered mixed and neighbourhoods with percentages above 24 are considered 'ethnically concentrated' neighbourhoods.
} 
high incomes are higher rated than neighbourhoods consisting of mainly low income households. For all three groups of respondents, the higher the average income in the neighbourhood, the higher the reputation of the neighbourhood is rated (correlation coefficients varying from 0.880 for lowest income households to 0.905 for the highest income households, $\mathrm{p}<0.0000$ ). Low income households rate low income neighbourhoods and middle income neighbourhoods higher than the two other groups do. Middle and high-income groups rate high income neighbourhoods higher than the low income groups. For 13 of the 24 neighbourhoods the reputation ratings of low and high income respondents differ significantly. Again, low income neighbourhoods are rated higher by low income respondents, while high-income neighbourhoods are rated higher by high income respondents. The only exception to this rule is Lombok, which is rated higher by high income groups, while it is still predominantly a low-income neighbourhood. Given the fact that Lombok is in the process of gentrification, this result is not surprising; Lombok is on its way to becoming a high-income neighbourhood in the future. All three groups give the poorest neighbourhood a similar low reputation rating. The reputation of this neighbourhood is possibly influenced by the local media, continuously emphasising the negative aspects of this neighbourhood.

Figure 6 shows reputation ratings by level of education of the respondents. A higher percentage of poorly educated people in the neighbourhood is associated with a lower neighbourhood rating for all three educational groups $(0.822$ for those with a low level of education to 0.841 for those with a high level of education, $\mathrm{p}<0.000$ ). All three groups rate neighbourhoods with a high share of middle- and highly-educated residents the highest, while neighbourhoods with a high share of low-educated residents are rated the lowest. Low-educated respondents rate areas with a high share of low-educated residents higher than the two other groups, while the latter rate neighbourhoods with a high share of middle- and highly-educated residents higher, though this is only true for areas where the proportion of low-educated residents is below 16 percent. Tests on the differences between the mean ratings of the three groups show that, in 13 cases, the differences between low and highly-educated people are significant. Here again, neighbourhoods with a high proportion of poorlyeducated people are more highly rated by low-educated households, while neighbourhoods with a large share of highly-educated residents are rated higher by highly educated households. Again, the gentrifying neighbourhood of Lombok is the only exception to this rule. The results indicate that low-educated residents rate neighbourhoods with a high average level of education higher than neighbourhoods with a low average level of education. At the same time, these low-educated residents are more positive about neighbourhoods with a low average level of education than other people are.

The analyses of the differences in neighbourhood ratings between income and educational groups both confirm hypothesis 3. Although all socioeconomic groups discern the same neighbourhood hierarchy, low-socioeconomic status groups are more positive about neighbourhoods with a low-socioeconomic status than groups with a higher socioeconomic status, while high-socioeconomic status groups are more positive about neighbourhoods with a high-socioeconomic status than groups with a lower-socioeconomic status. 
The results of this study showed that residents do assess the reputation of their own neighbourhood higher than non-residents, which is likely to be related to the fact that most residents will be positively biased towards the neighbourhood they have chosen to live in. Although neighbourhood reputations were found to be widespread views among the urban population (in terms of the hierarchy of neighbourhoods), various groups of non-residents were found to assess the reputation of particular neighbourhoods differently. Neighbourhood reputations were assessed more positively when the social composition of the neighbourhood matched the residents' ethnic and socio-economic characteristics. Furthermore we found that, although the reputation of a neighbourhood cannot be detached from its history and although reputation is based on subjective assessments, objective, contemporary neighbourhood characteristics are very good predictors of neighbourhood reputations. Social factors are especially good predictors in this respect.

We have several recommendations for future research on neighbourhood reputations. The role of the history of a particular neighbourhood in shaping its reputation is a factor that has not received much attention in this paper. We agree with Massey (1995) that every place has a history and that this history can be an important factor in determining the reputation of a neighbourhood. Several authors have studied the role of different actors in how images of neighbourhoods have come into existence over time (Damer, 1989; McLaren et al., 2005; Blokland 2008). We feel that discourse analysis, in combination with an ethnographic approach, can be a fruitful addition to our quantitative methods as they can shed more light on the dynamics of reputations and the shifting of power of actors in the construction of reputations.

Another gap in our knowledge is the effect of (negative) neighbourhood reputations on the behaviour of residents: how do residents react to a negative neighbourhood reputation? Does their willingness to participate in resident organization decrease? Does their propensity to move increase? Research in Australia (Palmer et al., 2004) suggests that a negative reputation can have a positive impact on participation in different social and civic activities whereas Wacquant (1993) argues that in the French and American context participation is negatively influenced by a negative reputation (cf. Blokland, 2008). We know that neighbourhood characteristics can play a role in understanding residential mobility (see Van Ham and Feijten, 2008; Van Ham and Clark, forthcoming). However, with one notable exception (Skifter Andersen, 2008), the reputation of the neighbourhood has not been used as a predictor of mobility behaviour.

Neighbourhood regeneration policies in Western-Europe generally aim to improve the life chances of current residents and aim to attract more affluent households from other areas. The success of attracting the 'right type' of new residents can be expected to partially depend on measures to improve the reputation of a neighbourhood. The most important determinants of neighbourhood reputations found in this study are the ethnic mix and the socioeconomic status of neighbourhoods. However, it would be far-fetched to expect that regeneration policies aimed at, for example, a change of the social composition of neighbourhoods are suitable to improve the reputation of neighbourhoods (Musterd, 2008). First, policies aimed at creating a social mix are often controversial (social engineering) because they appear to be at odds with ideas of social equity and individual choice (Crump, 2002). Displacement of residents can also result in the break down of important social 
structures in neighbourhoods because many of the existing residents are not able to return to their neighbourhood (Clampet-Lundquist, 2004). The resulting 'forced' new mix of residents can result in tension between old and new residents and to a (further) decline of social cohesion (Van Beckhoven and Van Kempen, 2003; Joseph et al., 2007).

Second, other studies have made clear that reputations are connected to the history of the neighbourhoods. Hastings and Dean (2003) showed in their study of a neighbourhood in Northeast England that the current reputation was mainly the related to the social class of its original (slum-clearance) residents of many years ago. It appears to be very difficult to change the history of a neighbourhood, and therefore changing an area's reputation may be a great challenge.

Third, there is evidence that artificially created socially mixed neighbourhoods will not be very sustainable because of selective mobility in and out of neighbourhoods. Van Ham and Feijten (2008) and Van Ham and Clark (forthcoming) have shown that residents (have the wish to) move away from neighbourhoods where the neighbourhood socioeconomic mix does not match their own characteristics. It is very ironic that creating sustainable mixed neighbourhoods might require substantial policy intervention to keep neighbourhoods mixed.

So what are the alternative policy measures to improve neighbourhood reputations without explicitly changing the social mix of neighbourhoods? Based on the above we argue that the expected results of policy will be rather limited. One possibility is to try to weaken the link made by the general urban population between neighbourhood reputations and socio-economic neighbourhood characteristics. A possible strategy to achieve this is by implementation of reputation management as an integral part of neighbourhood renewal policy (Hastings and Dean, 2003). Stakeholders, such as residents, welfare organisations, councils and prospective residents, should together create a vision of the desired image of the neighbourhood. Public relations are a significant part of this strategy: neighbourhood transformations (physical, functional and social) should be widely publicised in local media and on signs along main-arteries in the neighbourhood. Further, to attract non-residents to the neighbourhood, positive pull factors should be used such as shopping and entertainment facilities, and street festivals concentrating on the positive aspects of the concerning neighbourhoods. Finally, the building of landmarks on passageways may provide positive attention to the neighbourhood by outsiders.

\section{References}

Adams, J. S. (1969) Directional bias in intra-urban migration, Economic geography, 45, pp. 302-323.

Arthurson, K. (2001) Achieving social justice in estate regeneration: The impact of physical image construction, Housing Studies, 16, pp. 807-826.

Bauder, H. (2001) 'You're good with your hands, why don't you become an auto mechanic': Neighborhood context, institutions and career development, International Journal of Urban and Regional Research, 25, pp. 593-608.

Bauder, H. (2002), Neighbourhood effects and cultural exclusion, Urban studies, 39, pp. 85-93.

Bell, P. A., T.C. Greene, J.D. Fisher \& A. Baum (1996) Environmental psychology (Orlando, FL: Harcourt Brace College Publishers). 
Blokland, T. (2008) "You got to rember you live in public housing": Place-making in an American housing project. Housing, Theory and Society, 25, pp. 31-46.

Bobo, L. and C. L. Zubrinsky (1996) Attitudes on residential integration: Perceived status differences, mere in-group preference, or racial prejudice? Social Forces, 74, pp. 883-909.

Bolt, G.S. (2001) Wooncarrières van Turken en Marokkanen in ruimtelijk perspectief. Utrecht: Universiteit Utrecht.

Bolt G., R. Van Kempen R. and M. Van Ham (2008) Minority ethnic groups in the Dutch housing market: spatial segregation, relocation dynamics and housing policy, Urban Studies, 45, pp. 1359-1384.

Bolt, G., M. Van Ham and R. Van Kempen (2006). Allochtonen op de Woningmarkt. Ruimtelijke Segregatie en Verhuisdynamiek, in: F. Van Tubergen and I. Maas (eds.), Allochtonen in Nederland in international perspectief (Amsterdam, Amsterdam University Press).

Brattbakk, I. and T. Hansen (2004) Post-war large housing estates in Norway - Well kept residential areas still stigmatised? Journal of Housing and the Built Environment, 19, pp. 311-332

Burgess, E. W. (1967). The growth of the city. An introduction to a research project, in: R. E. Park and E. W. Burgess (Ed.), The city (Chicago: The University of Chicago Press).

Charles, C. Z. (2003) Dynamics of residential segregation, Annual review of sociology, 29, pp. 167-207.

Clampet-Lundquist, S. (2004) Hope VI relocation: Moving to new neighborhoods and building new ties, Housing Policy Debate, 15, pp. 415-447.

Clark, W. A. V. (1991) Residential preferences and neighborhood racial segregation: a test of the Schelling segregation model, Demography, 28, pp. 1-19.

Clark, W. A. V. (1992) Residential preferences and residential choices in a multiethnic context, Demography, 29, pp. 451-466.

Clark, W. A. V. and M. Cadwallader (1973) Residential preferences: an alternate view of intraurban space, Environment and planning, 5, pp. 693-703.

Congalton, A. A. (1969) Status and prestige in Australia (Melbourne: Cheshire).

Costa Pinto, T. (2000). Residential contexts of social exclusion: images and identities (Gävle: ENHR Conference 2000).

Costello, L. (2005) From prisons to penthouses: The changing images of high-rise living in Melbourne, Housing Studies, 20, pp. 49-62.

Crump, J. (2002) Deconcentration by demolition: public housing, poverty, and urban policy, Environment and Planning D: Society and Space, 20, pp. 581-596.

Curtis, R. F. and E. F. Jackson (1977) Inequality in American communities (New York, San Francisco, London: Academic Press).

Damer, S. (1989) From Moorepark to "Wine Alley": The rise and fall of a Glasgow housing scheme. (Edinburgh: Edinburgh University Press).

De Decker, P. and I. Pannecoucke (2004) The creation of the incapable social tenant in Flanders, Belgium. An appraisal, Journal of Housing and the Built Environment, 19, pp. 293-309.

Emerson, M., K. Chai and G. Yancey (2001) Does Race Matter in Residential Segregation? Exploring the Preferences of White Americans, American Sociological Review, 66, pp. 922-935.

Evans, G. W. (1980) Environmental cognition, Psychological bulletin, 88, pp. 259287. 
Festinger, L. (1957) A Theory of Cognitive Dissonance (Stanford: Stanford University Press).

Galster, G. (2001) On the nature of neighbourhood, Urban Studies, 38, pp. 21112124.

Galster, G. (2007).Should policy makers strive for neighbourhood social mix? An analysis of the Western European evidence base, Housing Studies, 22, pp. 523545.

Galster, G. and S. Killen (1995) The geography of metropolitan opportunity: A reconnaissance and conceptual framework, Housing Policy Debate, 6, pp. 7-43.

Garcia-Mira, R., C. Arce and J.S. Sabucedo. (1997) Perceived quality of neighbourhoods in a city in northwest Spain: an individual differences scaling approach, Journal of environmental psychology, 17, pp. 243-252.

Gärling, T. (1976) The structural analysis of environmental perception and cognition: a multidimensional scaling approach, Environment \& Behavior, 8, pp. 385-417.

GBA City of Utrecht (2006), Buurtmonitor (http://utrecht.buurtmonitor.nl/; accessed 20 february 2006)

Harris, D. (2001) Why are whites and blacks averse to black neighbors? Social Science Research, pp. 100-116.

Hastings, A. and J. Dean (2003) Challenging images: tackling stigma through estate regeneration, Policy \& Politics, 31, pp. 171-184.

Hortulanus, R. P. (1995) Stadsbuurten - bewoners en beheerders in buurten met uiteenlopende reputaties [Urban neighbourhoods - residents and managers in neighbourhoods with divergent reputations] (Den Haag: VUGA).

Hortulanus, R. P. (2000) The development of urban neighbourhoods and the benefit of indication systems, Social indicators research, pp. 209-224.

Hourihan, K. (1979) The evaluation of urban neighbourhoods: (1) Perception, Environment and Planning A, 11, pp. 1337-1353.

Hwang, S. and S. Murdock (1998) Racial Attraction or Racial Avoidance in American Suburbs, Social Forces, 77, pp. 541-566.

Ilhanfeldt, K. R. and B. Scafidi (2004) Whites' neighbourhood racial preferences and neighbourhood racial composition in the United States: Evidence from the multi-city study of urban inequality, Housing Studies, 19, pp. 325-359

Joseph, M. L., R.J. Chaskin and H.S. Webber (2007) The theoretical basis for addressing poverty through mixed-income development. Urban Affairs Review, 42, pp. 369-409.

Kearns, A. and M. Parkinson (2001) The significance of neighbourhood, Urban Studies, 38, pp. 2103-2110.

Keller, S. (1968) The Urban Neighborhood: A sociological perspective (New York: Random House).

Laumann, E. O., P. M. Siegel and R.W. Hodge. (1970). Stratification and the community, in: E. O. Laumann, P. M. Siegel and R. W. Hodge (eds.) The logic of social hierarchies, pp. 521-525 (Chicago: Markham publishing company).

Lee, B. A. and K. E. Campbell (1997) Common grounds? Urban neighborhoods as survey respondents see them, Social Science Quaterly, 78, pp. 922-936.

Logan, J. R. and O. A. Collver (1983) Residents' perceptions of suburban community differences, American Sociological Review, 48, pp. 428-433.

Massey, D. (1995) The conceptualization of space, in: D. Massey and P. Jess (Ed.) A place in the world? Places, cultures and globalization (Oxford: The Open University). 
May, D. M. (2004) The interplay of three established-outsider figurations in a deprived inner-city neighbourhood, Urban studies, 41, pp. 2159-2179.

McLaren, L. P., R., L. Carruthers and P. Hawe (2005) Introducing a means of quantifying community reputation: the print media as a data source, Health \& Place, 11, pp. 187-194.

Michelson, W. (1977) Environmental Choice, Human Behavior and Residential Satisfaction (New York: Oxford University Press).

Murie, A., T. Knorr-Siedow and R. Van Kempen (2003) Large estates in Europe. General developments and theoretical backgrounds. Restate report 1. Restructuring large-scale housing estates in European cities: Good practices and new visions for sustainable neighbourhoods and estates (Utrecht: URU).

Musterd, S. (2008) Residents' views on social mix: Social mix, social networks and stigmatisation in post-war housing estates in Europe, Urban Studies, 45, pp. 897-915.

Musterd, S. and R. Andersson (2005) Area-based policies: a critical appraisal, Tijdschrift voor Economische en Sociale Geografie, 96, pp. 377-389.

$\mathrm{O}+\mathrm{S}$ Amsterdam (2006) Amsterdam in Cijfers (http://www.os.amsterdam.nl/feitenencijfers/amsterdamincijfers2006; accessed on 30 March 2006)

Palmer, C., A. Ziersch, K. Arthurson and F. Baum (2004) Challenging the stigma of public housing: Preliminary findings from a qualitative study in South Australia, Urban Policy and Research, 22, pp. 411-426.

Permentier, M. (2003) De reputatie van Nederlandse concentratiebuurten. Een onderzoek naar de reputatie van Kanaleneiland (Utrecht: Universiteit van Utrecht) [masterthesis]

Permentier, M., M. v. Ham and G. Bolt (2007) Behavioural Responses to Neighbourhood Reputations, Journal of Housing and the Built Environment, 22, pp. 199-213.

Power, A. (1997) Estates on the edge. The social consequences of mass housing in Northern Europe (London: Macmillan).

Sampson, R. J. and S. W. Raudenbush (2004) Seeing disorder: neighborhood stigma and the social construction of broken windows, Social psychology quarterly, 67, pp. 319-342.

Schelling, T. (1969) Models of segregation, The American Economic Review, 59, pp. 488-493.

Schelling, T. C. (1971) Dynamic models of segregation, Journal of Mathematical Sociology, 1, pp. 143-186.

Semyonov, M. and V. Kraus (1982) The social hierarchies of communities and neighborhoods, Social science quarterly, 63, pp. 780-789.

Skifter Andersen, H. (2001). What is the special purpose of area based initiatives? How to understand deprived urban neighbourhoods?(Copenhagen: EURA Conference Copenhagen 2001).

Skifter Andersen, H. (2008) Why do residents want to leave deprived neighbourhoods? The importance of residents' subjective evaluations of their neighbourhood and its reputation, Journal of Housing and the Built Environment, 23, pp. 79-101.

Suttles, G. D. (1968) The social order of the slum. Ethnicity and territory in the inner city (Chicago, London: The University of Chicago Press).

Suttles, G. D. (1972) The social construction of communities (Chicago, London: The University of Chicago Press). 
Taylor, M. (1998), Combating the social exclusion of housing estates, Housing Studies, 13, pp. 819-832.

Teijmant, I. (1979) Buurtgebondenheid en verhuizen. Amsterdam: UvA Vakgroep sociologie en gebouwde omgeving.

Thill, J.-C. and D. Z. Sui (1993) Mental maps and fuzziness in space preferences, Professional geographer, 45, pp. 264-276.

Van Beckhoven, E. and R. Van Kempen (2003) Social effects of urban restructuring: a case study in Amsterdam and Utrecht, the Netherlands, Housing Studies, 18(6), 853-875.

Van der Meer, C. E. (1996) Monitoring van buurten: signalering en analyse van probleemcumulatie (Amsterdam: AME).

Van Ham, M. and P. Feijten (2008) Who wants to leave the neighbourhood? The effect of being different from the neighbourhood population on wishes to move, Environment and Planning A, 40, pp. 1151-1170.

Van Ham, M. and W.A.V. Clark (Forthcoming) Neighbourhood mobility in context: household moves and changing neighbourhoods in the Netherlands, Environment and Planning A.

Van Kempen, E. (1994) The Dual City and the Poor: Social Polarisation, Social Segregation and Life Chances, Urban Studies, 31, pp. 995-1005.

Wacquant, L. J. D. (1993) Urban outcasts: stigma and division in the black American ghetto and the French periphery, International Journal of Urban and Regional Research, 19, pp. 366-383.

Wassenberg, F. (2004) Renewing stigmatised estates in the Netherlands: A framework for image renewal strategies, Journal of Housing and the Built Environment, pp. 271-292.

Wilson, J. Q. and G. L. Kelling (1982) Broken Windows. The police and neighborhood safety (Washington D.C.: Atlantic Monthly).

Wilson, W. J. (1996). When work disappears (Chicago: The University of Chicago Press). 
Table and figure captions

Fig. 1

Location of Utrecht in the Netherlands

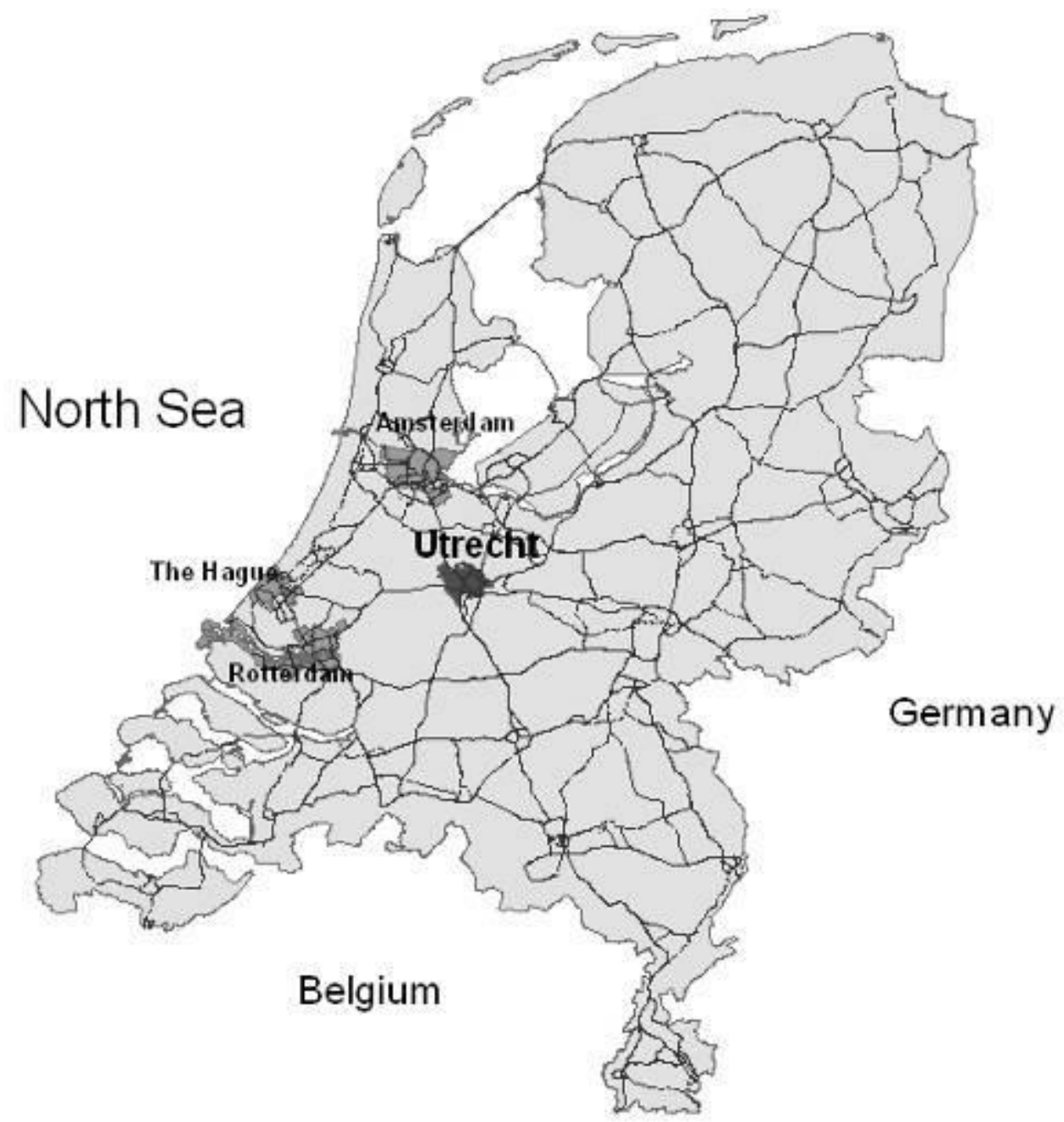

\section{Legend}

- Main roads

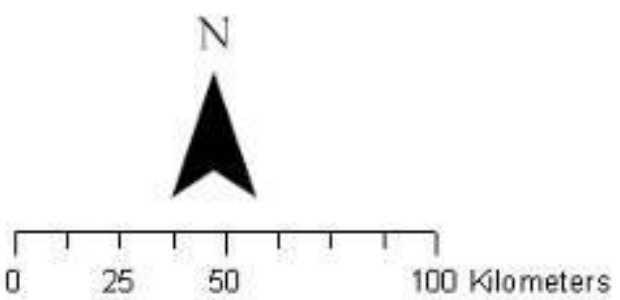


Fig. 2 Reputation ratings on a 5-point scale among neighbourhood residents, other city residents (OCR) and estate agents in Utrecht, 2006

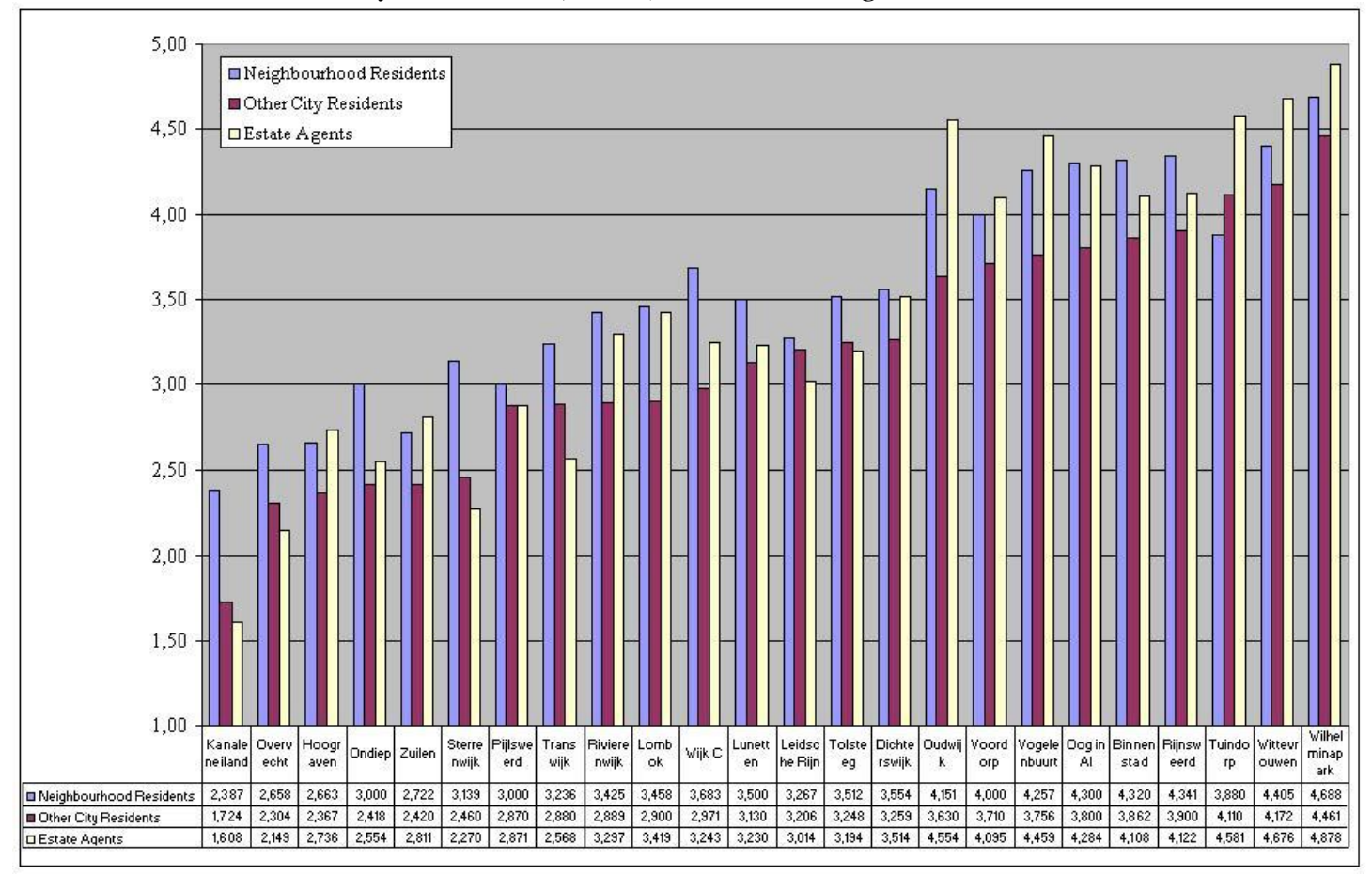

Fig. 3 Reputation ratings of 24 Utrecht neighbourhoods assigned by other city residents $(O C R)$ 


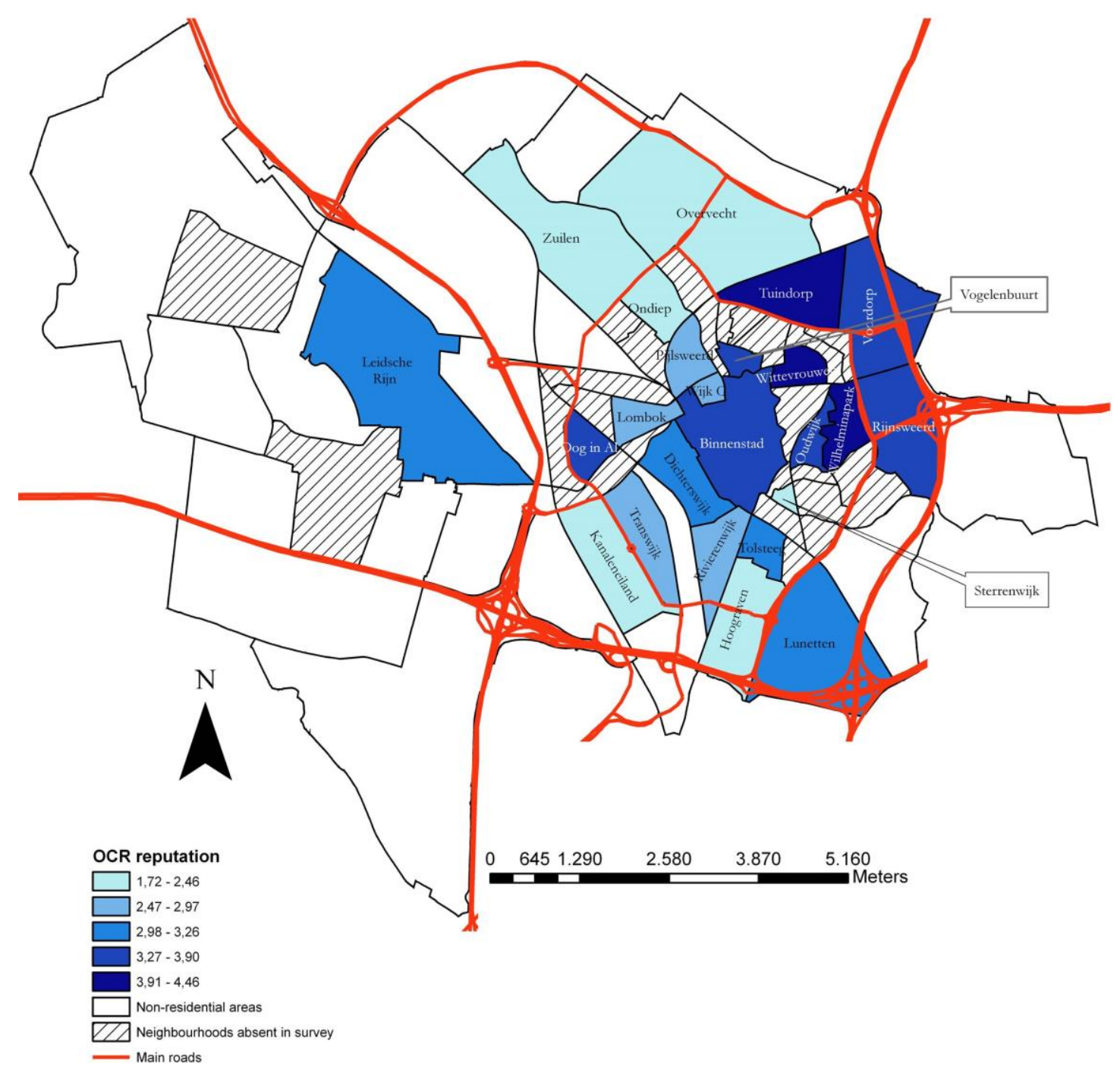


Fig. 4

Reputation ratings on a 5-point scale among native Dutch and nonwestern immigrants in Utrecht, 2006 (sorted from neighbourhood with highest to lowest percentage of non-western immigrants)

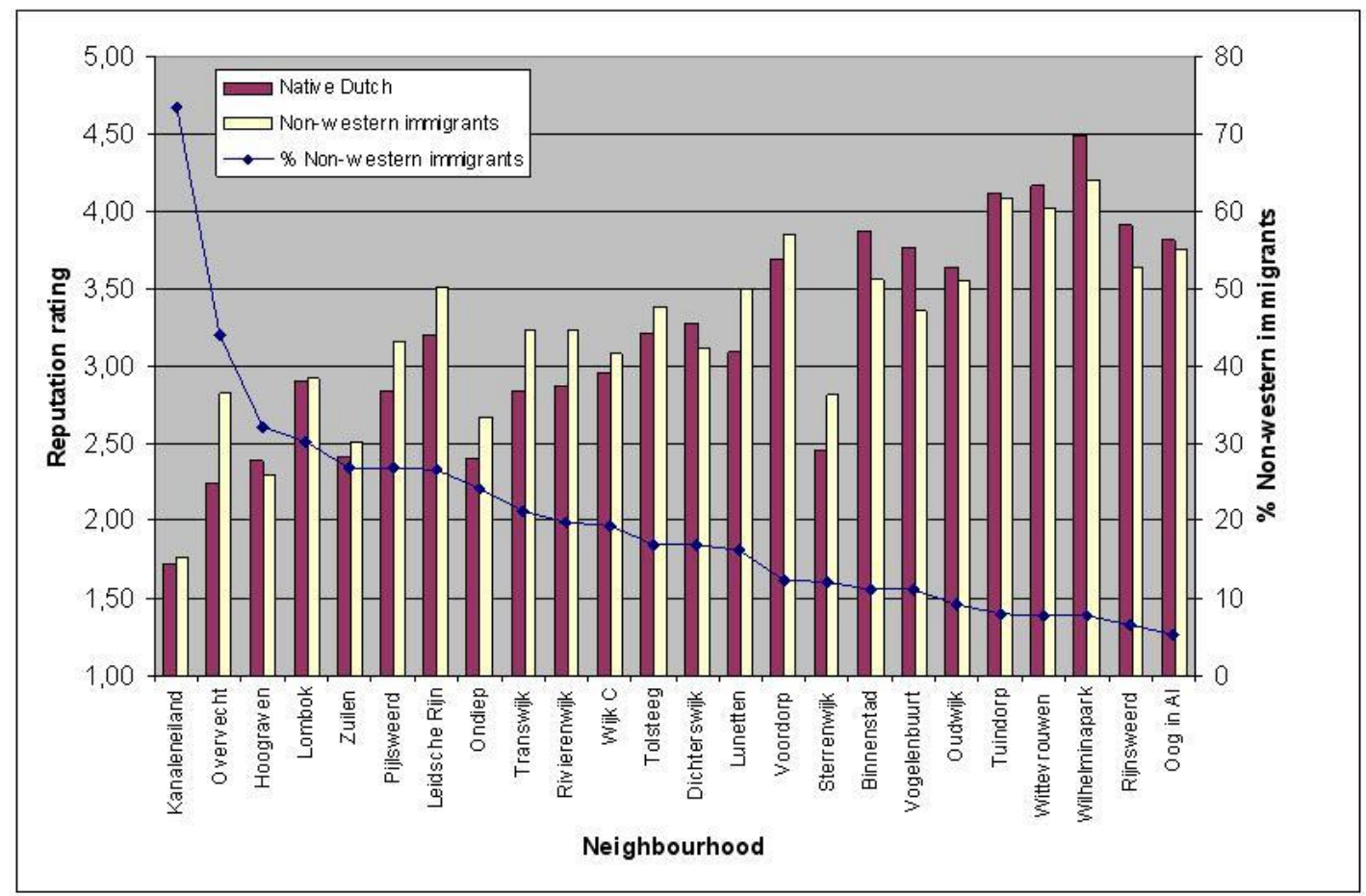


Fig. 5 Reputation ratings on a 5-point scale among three different income groups in Utrecht, 2006 (sorted from neighbourhood with lowest average income to highest average income)

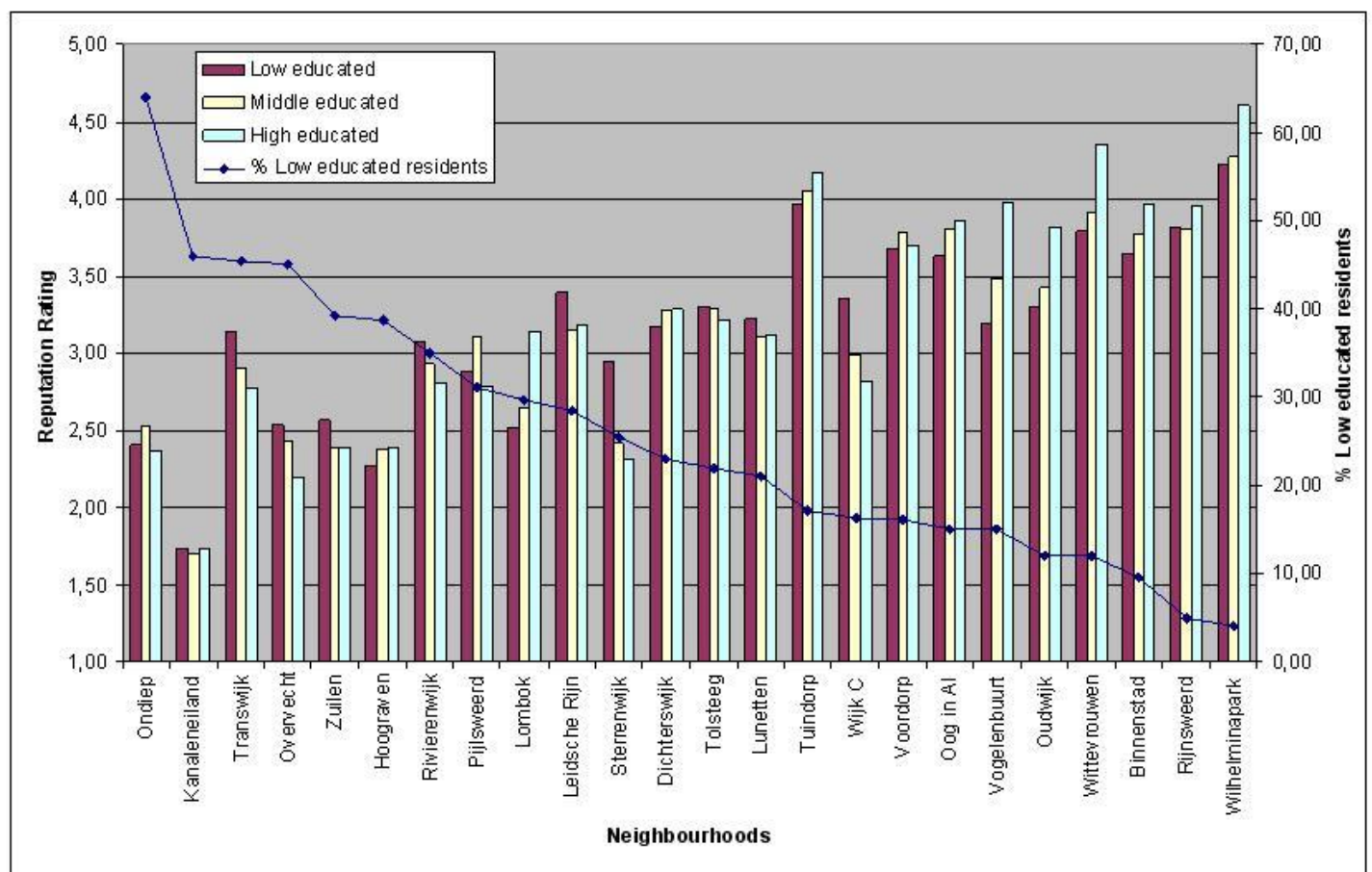


Fig. 6

Reputation ratings on 5-point scale among three different educated groups in Utrecht, 2006 (sorted from neighbourhood with highest percentage low educated to lowest percentage)

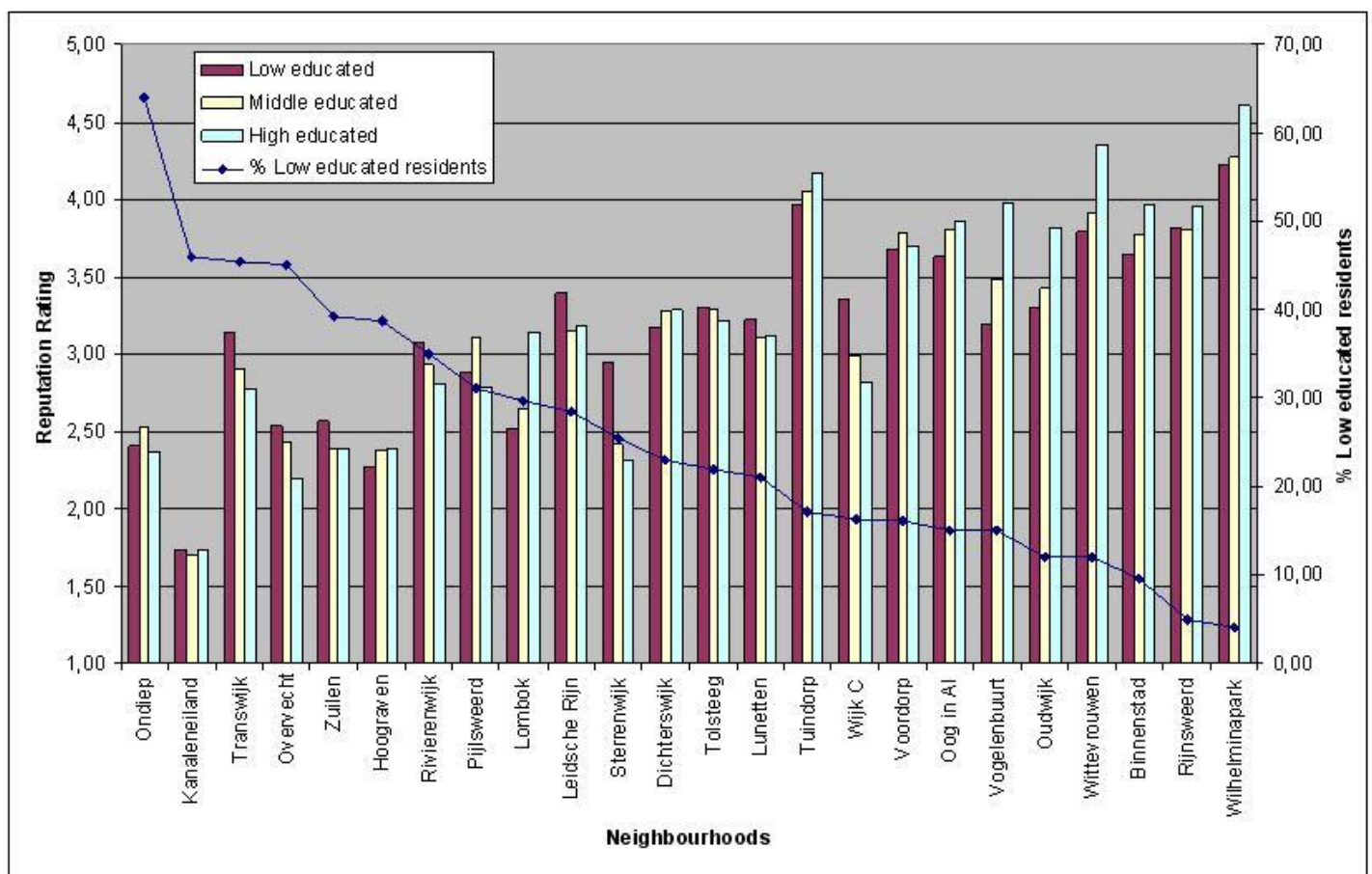


Table 1

Mean and standard deviation scores of the total 24 neighbourhoods by the three groups

\begin{tabular}{|l|l|l|}
\hline & Mean & Standard deviation \\
\hline Neighbourhood Residents & 3.564 & 0.713 \\
\hline Other city residents & 3.185 & 0.781 \\
\hline Estate agents & 3.426 & 0.593 \\
\hline
\end{tabular}

Table 2 Number of neighbourhoods with significant differences in the reputation assessments between the three groups

\begin{tabular}{|l|l|l|}
\hline & Other city residents & Estate agents \\
\hline Neighbourhood residents & $\begin{array}{l}21 \text { (in 20 cases more positive } \\
\text { assessed by neighbourhood } \\
\text { residents) }\end{array}$ & $\begin{array}{l}11 \text { (in } 7 \text { cases more positive } \\
\text { assessed by neighbourhood } \\
\text { residents }\end{array}$ \\
\hline Other city resident & -- & 12 (in 11 cases more positive \\
& & assessed by estate agents) \\
\hline
\end{tabular}

Table 3 Principal Component Analysis of neighbourhood characteristics 
Neighbourhood characteristics

Component

\begin{tabular}{|c|c|c|c|c|}
\hline & $\begin{array}{l}\text { Socioeconomicl } \\
\text { ethnicity }\end{array}$ & Urbanity & $\begin{array}{l}\text { Household } \\
\text { comp.ishops }\end{array}$ & Age \\
\hline Percentage of Multifamily dwellings 2004 & .497 & -.142 & .768 & .182 \\
\hline Address density $\left(\mathrm{km}^{2}\right) 2004$ & .073 & .833 & .450 & -.210 \\
\hline Population density $\left(\mathrm{km}^{2}\right) 2005$ & .222 & .835 & .145 & .228 \\
\hline Average age of houses 2004 & -.177 & .828 & .069 & .180 \\
\hline Green space ( $\mathrm{m}^{2}$ per 1000 residents) 2005 & -.299 & -.797 & .057 & -.037 \\
\hline $\begin{array}{l}\text { Number of govemment institutions (education, city, health) per } 1000 \\
\text { residents } 2005\end{array}$ & -.619 & .019 & .486 & -.228 \\
\hline Number of shops per 1000 residents 2005 & .003 & .148 & .707 & -.208 \\
\hline Distance to downtown in kilometres & .187 & -.663 & -.604 & .167 \\
\hline Percentage of non-westem immigrants 2006 & .822 & -.213 & .043 & 428 \\
\hline Percentage of single-person households 2006 & -.052 & .363 & .858 & -.053 \\
\hline Percentage of youth (24 and under) in relation to total population 2006 & .121 & .054 & -.499 & .770 \\
\hline $\begin{array}{l}\text { Percentage of elderly ( } 65 \text { years and older) in relation to total pop. } \\
2006\end{array}$ & .350 & -.323 & -.017 & -.577 \\
\hline Number of reported incidents of vandalism, annoyance, house & & & & \\
\hline $\begin{array}{l}\text { burglary, car burglary, violence per } 1000 \text { residents and employment } \\
\text { places } 2005\end{array}$ & .698 & .332 & .015 & -.035 \\
\hline Percentage of owner-occupation 2006 & -.880 & .004 & -.152 & .325 \\
\hline Percentage of unemployed (in relation to potertial labour force) 2005 & .949 & -.013 & .018 & .069 \\
\hline Percentage of poorly educated 2003 & 882 & -.058 & -.259 & -.175 \\
\hline Income per household 2002 & -.814 & -.304 & -.306 & .122 \\
\hline $\begin{array}{l}\text { Percentage of residents on welfare including individuals } 65 \text { years and } \\
\text { older } 2004\end{array}$ & .908 & .108 & .004 & .009 \\
\hline Initial Eigen Value & 6.167 & 4.702 & 2.452 & 1.111 \\
\hline
\end{tabular}

Extraction Method: Principal Components Analysis. Rotation Method: Varimax with Kaiser Normalization.

Rotation converged in 8 iterations.

Table $4 \quad$ Multiple regression analysis on three types of reputation 


\begin{tabular}{|c|c|c|c|c|c|c|c|c|c|}
\hline & \multirow{2}{*}{\multicolumn{3}{|c|}{$\begin{array}{c}\text { Internal Reputation } \\
\text { Neighbourhood residents }\end{array}$}} & \multicolumn{6}{|c|}{ External Reputation } \\
\hline & & & & \multicolumn{3}{|c|}{ Other city residents } & \multicolumn{3}{|c|}{ Estate agents } \\
\hline & B & Sign & Beta & B & Sign & Beta & B & Sign & Beta \\
\hline Constant & 3.564 & $* *$ & & 3.185 & $* *$ & & 3.426 & $* *$ & \\
\hline Socioeconomic/ethnicity & -0.598 & $* *$ & -0.926 & -0.659 & $* *$ & -0.941 & -0.819 & $* *$ & -0.908 \\
\hline Urbanity & 0.126 & $* *$ & 0.195 & 0.081 & & 0.116 & 0.244 & $* *$ & 0.270 \\
\hline Household comp/shops & 0.109 & $*$ & 0.168 & 0.055 & & 0.079 & 0.056 & & 0.062 \\
\hline Age & -0.004 & & -0.006 & 0.012 & & 0.017 & 0.089 & & 0.099 \\
\hline Chi-Square & 57.974 & & & 44.978 & & & 48.295 & & \\
\hline Df & 4 & & & 4 & & & 4 & & \\
\hline Sign. Chi & 0.000 & & & 0.000 & & & 0.000 & & \\
\hline $\mathrm{R}^{2}$ & 0.924 & & & 0.904 & & & 0.910 & & \\
\hline
\end{tabular}

$*=p<0.05 ; * *=p<0.01$

Method: Enter 